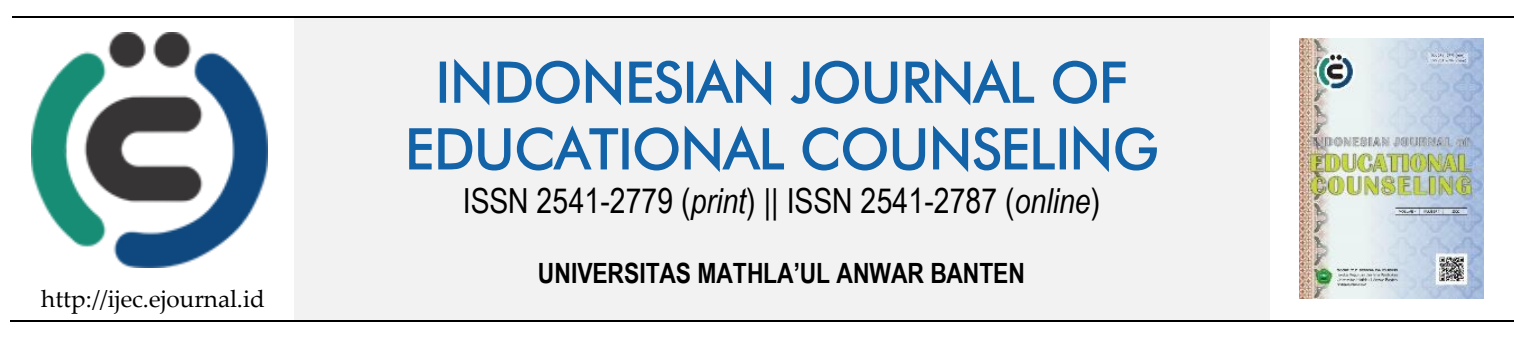

Research Based Article

\title{
Pengaruh Permainan Kooperatif dan Kecerdasan Interpersonal terhadap Regulasi Emosi Anak
}

\author{
Tisya Permatasari ${ }^{1}$, Hapidin $^{2}$, Karnadi $^{2}$ \\ 1,2 Universitas Negeri Jakarta, Indonesia
}

\begin{tabular}{ll}
\hline Article History & ABSTRACT \\
\hline Received: 27.06.2019 & THE EFFECT OF COOPERATIVE GAMES AND INTERPERSONAL \\
15.08.2019 revised form: & INTELLIGENCE ON CHILD EMOTIONAL REGULATION. Negative actions \\
Accepted: 19.12.2019 & that occur at this time are much related to one's emotional regulation ability. \\
Available online: 28.01.2020 & $\begin{array}{l}\text { For this reason, instilling the ability of motion regulations should be prepared } \\
\text { early. Interpersonal intelligence children like building, relationships and } \\
\text { maintaining social relationships will make it easier to know what kind of } \\
\text { emotion regulation affecting children. For this reason, cooperative games have } \\
\text { become a good game to do in increasing children's regulation. This study aims } \\
\text { to reveal the extent to which the influence of cooperative games and } \\
\text { interpersonal intelligence on the regulation of motions. Observational research } \\
\text { data were tested using a normality test and a homogeneity test followed by a } \\
\text { two-way variance test (ANAVA) and continued testing with tukey testing. The } \\
\text { results showed that the sample data were normally distributed and } \\
\text { homogeneous. The results of the analysis also showed the existence of the } \\
\text { interaction of cooperative games and interpersonal intelligence on regulation } \\
\text { based on the results of the analysis of variance F count }=62.52>\text { F tab = 4.08 at } \\
\text { the significant level }=0.05 .\end{array}$ \\
& KEYwORDS: Cooperative Play, Emotion Regulation, Interpersonal Intelligence.
\end{tabular}

DOI: $10.30653 / 001.202041 .120$

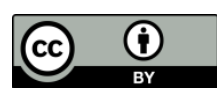

This is an open access article distributed under the terms of the Creative Commons Attribution 4.0 International License, which permits unrestricted use, distribution, and reproduction in any medium, provided the original work is properly cited. (c) 2020 Tisya Permatasari, Hapidin, Karnadi.

\section{PENDAHULUAN}

Regulasi emosi merupakan hal yang sangat penting diajarkan pada setiap individu. Terlihat dalam peraturan menteri pendidikan nasional republik indonesia nomor 137 tahun 2014 tentang standar pendidikan anak usia dini menyebutkan kemampuan mengendalikan emosi (emotion regulation) menjadi salah satu kriteria standar pencapaian perkembangan emosi anak usia dini. Kepentingan untuk mengontrol emosi juga di tegaskan oleh Santrock dengan menyatakan bahwa regulasi emosi merupakan dimensi penting dari perkembangan emosi (Santrock, 2010).

${ }^{1}$ Corresponding author's address: Program Studi Bimbingan dan Konseling, FIP Universitas Negeri Jakarta. Jl. Rawamangun Muka, RT.11/RW.14, Rawamangun, Kec. Pulo Gadung, Kota Jakarta Timur, Daerah Khusus Ibukota Jakarta 13220, Indonesia. Email: tisyapermatasari_paud17s2@mahasiswa.unj.ac.id 
Kajian tentang regulasi emosi dikemukakan oleh Gross dengan mengartikan regulasi emosi sebagai strategi yang dilakukan secara sadar ataupun tidak sadar untuk mempertahankan/ memperkuat/ mengurangi satu atau lebih aspek dari respon emosi yaitu pengalaman emosi dan perilaku baik itu emosi positif/ negatif (Gross, 2014). Eisenberg mengartikan regulasi emosi sebagai proses mengenali, menghindari, menghambat, mempertahankan mengelola kemunculan, bentuk, intensitas maupun masa berlangsungnya perasaan internalnya dalam rangka memenuhi afek biologis / adaptasi sosial / meraih tujuan individual (Eisenberg, 2010).

Mengembangkan kemampuan regulasi emosi akan memberi dampak keharmonisan terhadap lingkungan sekitar anak dan membentuk hubungan sosial yang baik dengan orang lain (Santrock, 2014). Hasil penelitian menunjukkan bahwa anak yang mampu meregulasi emosi memiliki keunggulan intelektual seperti keterampilan memecahkan masalah dibandingkan dengan anak yang mengalami satu emosi yang terus menerus menarik perhatiannya (Davis \& Levine, 2013). Hal ini dikarenakan, emosi memiliki peran untuk mengarahkan perhatian akan informasi dimana individu dapat memahami dan menanggapi perubahan dari tujuan awal yang telah ditentukan (Gross \& Thompson, 2014).

Penelitian lainnya menunjukkan bahwa ketidakmampuan untuk meregulasi emosi merupakan faktor risiko penting dalam pembentukan perilaku agresif (Ro \& Petermann, 2012). Hal ini menyebabkan sering terjadi kesalahpahaman antara anak yang satu dengan anak yang lain, sehingga menimbulkan konflik seperti saling mengejek atau saling memukul. Anak yang tidak bisa mengendalikan emosinya biasanya akan mengalami lack of social skills. Hal tersebut terjadi akibat anak kurang mampu menjalin komunikasi yang baik, mengekspresikan perasaan negatif tanpa menyakiti orang lain, mengatasi konflik tanpa melalui pertengkaran

Papalia dalam bukunya mengungkapkan bahwa anak membutuhkan latihan dan proses belajar untuk mengatur emosi-emosi negatif dalam dirinya (Papalia \& Old, 2010). Menurut penelitian yang dilakukan oleh Dewi menyimpulkan bahwa penerapan metode bermain dapat meningkatkan kemampuan sosial emosional pada anak (Dewi, Asri, \& Putra, 2016). Permainan kooperatif baik digunakan untuk merangsang kecerdasan interpersonal anak yang berdampak terhadap regulasi emosi anak.

Berdasarkan ulasan di atas, maka perlu dilakukan penelitian eksperimental tentang pengaruh permainan kooperatif dan kecerdasan interpersonal terhadap regulasi emosi pada anak usia 5-6 tahun di TK untuk mengungkap sejauh mana Pengaruh Permainan Kooperatif dan Kecerdasan Interpersonal Terhadap Regulasi Emosi.

\section{METODE}

Penelitian ini dilakukan dengan metode eksperimen dengan membandingkan permainan kooperatif secara kompetisi dan permainan kooperatif tanpa kompetisi dalam kelompok dengan variabel moderatornya kecerdasan interpersonal.

Desain yang digunakan pada penelitian ini adalah rancangan desain treatment by level $2 \times 2$. Adapun desain penelitian ini terbagi atas tiga variabel dengan rincian variabel terikat dibentuk menjadi dua bagian yaitu variabel perlakuan menggunakan permainan kooperatif secara kompetisi dan permainan kooperatif tanpa kompetisi. (A), variabel atribut yaitu kecerdasan interpersonal yang terdiri dari kecerdasan interpersonal tinggi 
dan kecerdasan interpersonal rendah. (B), sedangkan variabel bebasnya adalah regulasi emosi.

Penelitian ini dilaksanakan pada TK di Tangerang selatan, tepatnya di kelurahan Pamulang barat yaitu TK Pertiwi Pamulang dan Pamulang Timur yaitu pada TK Amanah At-Taqwa. Subyek pada penelitian ini adalah anak TK Pertiwi Pamulang sejumlah 32 anak dan TK Amanah At-Taqwa berjumlah 32 anak. Adapun kisi-kisi instrumen pada penelitian ini terbagi menjadi dua, yaitu kisi-kisi instrumen kecerdasan interpersonal dan kisi-kisi instrumen regulasi emosi

Tabel 1. Kisi-kisi Instrumen Kecerdasan Interpersonal

\begin{tabular}{lllll}
\hline No. & Aspek & Indikator & $\begin{array}{l}\text { No. Butir } \\
\text { Item }\end{array}$ & Jumlah \\
\hline 1 & Berempati & $\begin{array}{l}\text { Anak memiliki sensitivitas yang tinggi } \\
\text { terhadap perasaan orang lain. }\end{array}$ & $1,7,13$ & 3 \\
& & $2,8,14$ & 3 \\
\hline 2 & $\begin{array}{l}\text { Senak memiliki rasa peduli. } \\
\text { Bergaul }\end{array}$ & $\begin{array}{l}\text { Anak senang berinteraksi dengan orang di } \\
\text { sekitarnya }\end{array}$ & $3,9,15$ & 3 \\
& $\begin{array}{l}\text { Anak senang mengungkapkan perasaan } \\
\text { dengan cara verbal/ non verbal }\end{array}$ & $4,10,16$ & 3 \\
\hline 3 & $\begin{array}{l}\text { Mudah } \\
\text { Beradaptasi }\end{array}$ & $\begin{array}{l}\text { Anak mampu menyesuaikan diri dengan } \\
\text { lingkungannya } \\
\text { Anak mudah membuat teman }\end{array}$ & $5,11,17$ & 3 \\
\hline
\end{tabular}

Tabel 2. Kisi-kisi Instrumen Regulasi Emosi

\begin{tabular}{lllll}
\hline No. & Aspek & Indikator & $\begin{array}{l}\text { No. Butir } \\
\text { Item }\end{array}$ & Jumlah \\
\hline 1 & Mengatur & Anak mampu mempertahankan emosi & $1,7,13$ & 3 \\
& Emosi & Anak mampu mengurangi emosi & $2,8,14$ & 3 \\
\hline 2 & Mengatur & Anak mampu mengatur lamanya emosi & $3,9,15$ & 3 \\
& Intensitas & berlangsung & $4,10,16$ & 3 \\
& Emosi & Anak mampu mengatur intensitas & & \\
& & kemunculan emosi & & 3 \\
\hline 3 & Mengatur & Anak mampu mengatur intonasi suara saat & $5,11,17$ & 3 \\
& Ekspresi & merasakan emosi & & \\
& Emosi & Anak mampu mengatur pergerakan otot & $6,12,18$ & 3 \\
\hline Jumlah & & & 18 \\
\hline
\end{tabular}

Data yang didapat pada penelitian ini dianalisis sesuai dengan tujuan dan pernyataan penelitian. Teknik analisis data yang digunakan adalah analisis data deskriptif dimana menvisualisasikan data dalam bentuk gambar grafik histrogram dan analisis inferensial yang terdiri dari dua tahap pengujian yaitu uji persyaratan normalitas dan uji persyaratan homogenitas selanjutnya Hipotesis pada penelitian ini diuji menggunakan teknik analisis varian (ANAVA) dua jalur $2 \times 2$. Hal ini bertujuan untuk menguji efek utama A dan efek utama B serta pengaruh interaksi antara A dan B (main effect dan interaction effect). 


\section{HASIL DAN PEMBAHASAN}

\section{Uji Normalitas}

Hasil perhitungan uji normalitas pada semua data kelompok penelitian diketahui bahwa L hitung untuk semua kelompok lebih kecil dari pada L tabel, ini berarti menunjukkan nahwa semua kelompok penelitian berdistribusi normal. Hasil perhitungan uji coba normalitas dengan uji Liliefors secara keseluruhan

Tabel 3. Rangkuman Hasil Uji Normalitas Keseluruhan Data

\begin{tabular}{llll}
\hline Kelompok & $\mathrm{N}$ & L hitung & L tabel \\
\hline A1 & 22 & 0,099415 & 0,184 \\
\hline A2 & 22 & 0,07292 & 0,184 \\
\hline B1 & 22 & 0,154692 & 0,184 \\
\hline B2 & 22 & 0,113189 & 0,184 \\
\hline A1B1 & 11 & 0,156173 & 0,2506 \\
\hline A1B2 & 11 & 0,158415 & 0,2506 \\
\hline A2B1 & 11 & 0,127864 & 0,2506 \\
\hline A2B2 & 11 & 0,099989 & 0,2506 \\
\hline
\end{tabular}

\section{Uji Homogenitas}

Hasil perhitungan uji homogenitas dari ketiga kelompok data diperoleh $X^{2}$ hitung lebih kecil dari $X^{2}$ tabel berdasarkan taraf $\alpha=0,05$. Maka dapat disimpulkan keempat kelompok data mempunyai varians yang sama besar, maka kelompok data tersebut bersifat homogeny. Hasil pengujian normalitas dan homogenitas dari data tersebut menunjukkan bahwa kelompok-kelompok data pada penelitian ini berasal dari populasi yang berdistribusi normal dan memiliki varians data yang homogeny. Berdasarkan hal tersebut maka pernyaratan untuk melakukan pengujian hipotesis dengan analisis varians (ANAVA).

Tabel 4. Rangkuman Hasil Uji Homogenitas Varians Kelompok Data

\begin{tabular}{ccc}
\hline Kelompok & $X^{2}$ hitung & $X^{2}$ tabel \\
\hline A1 dan A2 & 0,28943 & 3,841 \\
\hline B1 dan B2 & 0,1128 & 3,841 \\
\hline A1B1, A1B2, A2B1, A2B2 & 0,1128 & 7,815 \\
\hline
\end{tabular}

Tabel 5. Rangkuman Hasil Perhitungan ANAVA Dua Jalur

\begin{tabular}{llllll}
\hline $\begin{array}{l}\text { Sumber } \\
\text { Varians }\end{array}$ & JK & Db & RJK & F hit & $\begin{array}{l}\text { F tab } \\
\alpha=0,05\end{array}$ \\
\hline Antar A & 61,427 & 1 & 61,427 & 16,64 & 4,08 \\
\hline Antar B & 86,11 & 1 & 86,11 & 23,33 & 4,08 \\
\hline Interaksi AXB & 230,7 & 1 & 230,7 & 62,52 & 4,08 \\
\hline Dalam & 151,47 & 41 & 3,69439 & & \\
\hline Total & 529,707 & 44 & & & \\
\hline
\end{tabular}

Dari hasil analisis diketahui nilai $\mathrm{F}_{\mathrm{OA}}=16,64$. Dari tabel daftar- $\mathrm{H}$ pada $\mathrm{db}(\mathrm{A}) / \mathrm{db}(\mathrm{D})=$ 1/41, dan $\alpha=0,05$ diketahui nilai Ftabel $=4,02$ karena $\mathrm{F}_{(\mathrm{OA})}=16,64$ atau Ho ditolak, jadi 
terdapat perbedaan rata-rata regulasi emosi antara anak yang bermain kooperatifkompetisi dan anak yang bermain kooperatif tanpa kompetisi.

Dari hasil analisis diketahui nilai $\mathrm{F}_{\mathrm{OB}}=23,33$ Dari tabel daftar- $\mathrm{H}$ pada $\mathrm{db}(\mathrm{A}) / \mathrm{db}(\mathrm{D})=$ 1/41, dan $\alpha=0,05$ diketahui nilai Ftabel $=4,02$ karena $\mathrm{F}_{(\mathrm{OA})}=23,33$ atau Ho ditolak, jadi terdapat perbedaan rata-rata regulasi emosi antara anak yang memiliki kecerdasan interpersonal tinggi dan anak yang memiliki kecerdasan interpersonal rendah.

Dari hasil analisis diketahui nilai $\mathrm{F}_{(\mathrm{OAB})}=62,52$. Dari tabel daftar- $\mathrm{H}$ pada $\mathrm{db}(\mathrm{a}) / \mathrm{db}(\mathrm{D})$ $=1 / 41$, dan $\alpha=0,05$ diketahui nilai $\mathrm{F}$ tabel $=4,02$ karena $\mathrm{F}_{(\mathrm{OAB})}=62,52$ atau Ho ditolak, jadi terdapat pengaruh interaksi antara permainan kooperatif dan kecerdasan interpersonal terhadap regulasi emosi anak sesuai dengan tinggi rendahnya kecerdasan interpersonal anak.

\section{Uji Lanjutan Tukey}

Dari hasil analisis diketahui bahwa nilai Qhitung A1B1 - A2B1 $=6,496$. Dari tabel Critical Value Of $Q$ ( TUKEY) dengan $\alpha=0,05, \mathrm{k}=4$ dan $\mathrm{n}=14$ diketahui nilai Qtabel $=4,25$. Karena Qhitung A1B1-A2B1 $=6,496>$ Qtabel $=4,25$ atau Ho ditolak, maka regulasi emosi yang dihasilkan dengan bermain kooperatif dengan cara kompetisi dan memiliki kecerdasan interpersonal tinggi lebih tinggi daripada anak yang bermain kooperatif tanpa kompetisi dan memiliki kecerdasan interpersonal tinggi.

Tabel 6. Hasil Perhitungan Lanjutan Uji Tukey

\begin{tabular}{|c|c|c|c|}
\hline Kelompok & $\mathrm{N}$ & $Q_{\text {hitung }}$ & $Q_{\text {tabel }}$ \\
\hline & & & $(\alpha=0,05)$ \\
\hline A1B1 dan A2B1 & 11 & 6,496 & 4,25 \\
\hline $\mathrm{A} 1 \mathrm{~B} 2$ dan $\mathrm{A} 2 \mathrm{~B} 2$ & 11 & 7,5791 & 4,25 \\
\hline
\end{tabular}

Dari hasil analisis diketahui bahwa nilai Qhitung A1B2 - A2B2 $=7,5791$. Dari tabel Critical Value Of $Q$ ( TUKEY) dengan $\alpha=0,05, \mathrm{k}=4$ dan $\mathrm{n}=14$ diketahui nilai Qtabel $=4,25$. Karena Qhitung A1B2-A2B2 = 7,5791 > Qtabel $=4,25$ atau Ho ditolak, maka regulasi emosi yang dihasilkan dengan bermain kooperatif dengan cara kompetisi dan memiliki kecerdasan interpersonal rendah lebih tinggi daripada anak yang bermain kooperatif tanpa kompetisi dan memiliki kecerdasan interpersonal rendah.

Tabel 7. Deskripsi Data Analisis Tendensi Sentral

\begin{tabular}{lll}
\hline & $\begin{array}{l}\text { Eksperimen (permainan } \\
\text { kooperasi }- \text { kompetitif) }\end{array}$ & $\begin{array}{l}\text { Kontrol (permainan kooperasi } \\
\text { non kompetitif) } \\
\text { A2 }\end{array}$ \\
\hline Kecerdasan & $\mathrm{N}=11$ & $\mathrm{~N}=11$ \\
Interpersonal & Mean $=50,5455$ & Mean $=48,3636$ \\
(B1) & Median $=51$ & Median $=48$ \\
& Modus $=52$ & Modus $=50$ \\
& $\mathrm{SD}=1,4397$ & $\mathrm{SD}=1,74773$ \\
\hline \multirow{2}{*}{ Kecerdasan } & $\mathrm{N}=11$ & $\mathrm{~N}=11$ \\
Interpersonal & Mean $=45,3636$ & $\mathrm{Mean}=42,8182$ \\
(B2) & Median $=45$ & Median $=43$ \\
& $\mathrm{Modus}=43$ & $\mathrm{Modus}=45$ \\
& $\mathrm{SD}=1,9633$ & $\mathrm{SD}=2,48267$ \\
\hline
\end{tabular}


Perbedaan regulasi emosi pada kelompok anak yang bermain permainan kooperatif dengan cara kompetisi dan kelompok anak yang bermain permainan kooperatif tanpa kompetisi (Antar A)

Berdasarkan hasil dari pengolahan data dan perhitungan yang telah dilakukan sebelumnya terbukti bahwa terdapat perbedaan anatara anak yang bermain permainan kooperatif yang dilakukan secara kompetisi dan anak yang bermain permainan kooperatif tanpa kompetisi. Hasil penelitian telah menunjukkan bahwa secara keseluruhan kelompok anak yang bermain permainan kooperatif secara kompetisi lebih tinggi dibandingkan dengan kelompok anak yang bermain permainan kooperatif tanpa kompetisi. Berdasarkan hal tersebut dapat dinyatakan bahwa permainan kooperatif secara kompetisi memiliki keunggulan dibandingkan permainan kooperatif tanpa kompetisi dalam mempengaruhi regulasi emosi pada anak.

Temuan dari hasil penelitian ini dapat dibuktikan bahwa bermain permaian kooperatif secara kompetisi ditaman kanak-kanak lebih efektif dibandingkan bermain kooperatif tanpa kompetisi yang mempengaruhi regulasi emosi anak. Peneliti menemukan bahwa bermain permainan kooperatif secara kompetisi membantu anak untuk mengatur emosi-emosi atau perasaan-perasaan dan menjaga emosi tersebut agar tidak berlebihan selama penyelesai masalah berlangsung. Serupa yang disampaikan oleh Santrock bahwa memahami bentuk-bentuk emosi yang ditampilkan orang lain dan mengendalikan emosinya sendiri merupakan bentuk perkembangan emosi di masa awal kanak-kanak (Santrock, 2010). Anak yang terlibat dalam kompetisi akan belajar memahami perasaan orang lain dan menghargai pendapat orang lain. Hal lainnya yang terlihat dari bermain kooperatif secara kompetisi adalah dapat mempererat hubungan dengan teman sebaya serta membantu mengelola kesuksesan dan kegagalan. Interaksiinteraksi ini membantu mereka membentuk hubungan sosial yang baik dengan orang lain.

\section{Interaksi antara permainan kooperatif dengan kecerdasan interpersonal terhadap regulasi emosi (INT A x B)}

Peneliti menemukan bahwa kecerdasan seseorang untuk berhubungan dengan orang disekitarnya yang meliputi kemampuan mengerti dan memahami perasaan orang lain, menciptakan relasi dan mempertahankan relasi sosialnya sehingga dapat bekerja sama dalam suatu team dengan baik sangat mempengaruhi kemampuan regulasi emosi anak. Peneliti melihat bahwa bermain kooperatif secara kompetisi dan kecerdasan interpersonal yang tinggi memberikan kontribusi yang besar terhadap regulasi emosi anak, Hal ini disebabkan karena kecerdasan interpersonal yang ideal terlihat dari kemampuan mengerti dan memahami perasaan orang yang disebut dengan empati. Dengan mempunyai kemampuan empati yang baik, seseorang akan mudah membangun hubungan dengan orang lain dan membina hubungan tersebut dalam waktu yang lama.

Peneliti melihat selama penelitian anak yang memiliki kecerdasan interpersonal yang tinggi tidak pernah ragu untuk menjalin hubungan dengan siapapun dan senang bermain kooperatif. Hal ini yang membantu anak untuk memahami lebih dalam emosiemosi yang dirasakan diri sendiri maupun yang ditampilkan orang lain. Kecerdasan interpersonal yang tinggi juga baik dalam memimpin sebuah kelompok terlihat saat anak menyelesaikan masalah yang sedang dihadapi secara kelompok dimulai dari perencanaan sampai dengan proses penyelesaian masalah dapat diselesaikan secara 
bersama-sama. Hal ini menunjukkan pentingnya interaksi yang terjalin antar anak yang membentuk emosi anak. Berdasarkan temuan yang diperoleh pada penelitian ini dapat disimpulkan bahwa terdapat interaksi antara permainan kooperatif dan kecerdasan interpersonal terhadap regulasi emosi anak.

Perbedaan regulasi emosi antara kelompok anak yang bermain permainan kooperatif dengan cara kompetisi dan anak yang bermain permainan kooperatif tanpa kompetisi pada anak yang memiliki kecerdasan interpersonal tinggi

Hasil penelitian telah menunjukkan bahwa kelompok anak yang memiliki kecerdasan interpersonal yang tinggi dan bermain permainan kooperatif secara kompetisi lebih tinggi dari pada kelompok anak yang bermain permainan kooperatif tanpa kompetisi. Berdasarkan hal tersebut dapat dinyatakan kelompok anak yang memiliki kecerdasan interpersonal yang tinggi sebaiknya bermain permainan yang bersifat kelompok yang memudahkan anak berinteraksi intens terhadap anak lainnya yang berdampak terhadap emosi anak.

Peneliti menemukan bahwa permainan kooperatif secara kompetisi mendorong anak untuk tetap fokus terhadap penyelesaian sebuah masalah yang dihadapi secara bersama dan memiliki motivasi yang besar terhadap pembelajaran yang berlangsung. Anak-anak menunjukkan antusias yang tinggi untuk menyelesaikan masalah yang dihadapi serta sikap yang ditunjukkan anak juga sangat berbeda selama pembelajaran berlangsung seperti duduk rapih tiap kelompok serta mendengarkan instruksi yang diberikan guru. Sikap yang ditunjukkan anak ini tidak terlepas dari bagaimana anak meregulasi emosi yang dirasakannya. Mengendalikan emosi selama proses penyelesaian masalah berlangsung sampai mengendalikan emosi saat mengalami kemenangan maupun kekalahan. Peneliti menemukan bahwa anak yang memiliki kecerdasan interpersonal yang tinggi akan menunjukkan sikap empati yang besar terhadap orangorang disekitarnya, terlihat bahwa beberapa anak yang mengalami kekalahan saat bermain menunjukkan ekspresi positif saat melihat salah satu kelompok memperoleh kemenangan yang ditunjukkan dengan memberikan apresiasi dengan bertepuk tangan, memberikan selamat serta tersenyum.

Perbedaan regulasi emosi antara kelompok anak yang bermain permainan kooperatif dengan cara kompetisi dan anak yang bermain permainan kooperatif tanpa kompetisi pada anak yang memiliki kecerdasan interpersonal rendah

Kecerdasan interpersonal seorang anak tidak dapat muncul dengan sendirinya, dibutuhkan latihan untuk dapat mengembangkan kecerdasan interpersonal seorang anak. Disinilah peran guru sebagai pendidik anak usia dini untuk memberikan latihan keterampilan sosial kepada anak sejak usia dini. Anak usia dini dibiasakan untuk bersosialisasi dengan teman-teman sebaya, agar kemampuan sosial seperti komunikasi, simpati, empati, mau berbagi, dan saling bekerjasama dapat terjalin. Apabila anak memiliki kecerdasan interpersonal yang baik, maka anak akan mudah menyesuaikan diri dalam situasi atau lingkungan baru yang akan dihadapinya, baik itu dalam lingkungan keluarga, lingkungan teman sebaya dan lingkungan sekolah.

Penelitian ini menemukan bahwa kecerdasan interpersonal yang rendah dari beberapa anak menunjukkan kurangnya anak melakukan aktivitas-aktivitas yang melibatkan interaksi terhadap orang lain sehingga berdampak terhadap perkembangan 
emosi anak tersebut. Kurangnya sosialisasi membuat anak tidak mengerti bentuk-bentuk emosi yang dirasakan diri sendiri maupunn yang ditampilkan orang lain. Namun dalam penelitian yang telah dilakukan membuktikan bahwa dengan melakukan bermain permainan kooperatif secara kompetisi memaksa anak terlibat dalam situasi sosial bersama anak yang lainnya. Hal ini akan membantu anak untuk berperan aktif dalam kelompok, berkomunikasi serta berinteraksi dengan anggota kelompoknya. Anak-anak yang memiliki kecerdasan interpersonal yang rendah menunjukan ekspresi emosi yang baik selama pembelajaran. Hal ini menunjukan bahwa dengan bermain permainan kooperatif secara kompetisi dapat mengarahkan anak untuk mengenal lebih dalam orangorang yang berada disekelilingnya. Sebaliknya beberapa anak yang memiliki kecerdasan interpersonal rendah bermain permainan kooperatif tanpa kompetisi lebih pasif (tidak mengikutsertakan dirinya) selama pembelajaran berlangsung terlihat anak-anak hanya mengandalkan teman yang memiliki antusias tinggi terhadap pembelajaran.

\section{SIMPULAN}

Berdasarkan hasil analisis data, pengujian hipotesis dan pembahasan hasil penelitian, maka dapat diambil kesimpulan bahwa secara keseluruhan regulasi emosi pada kelompok anak yang diberikan permainan kooperatif secara kompetisi lebih tinggi dibandingkan dengan kelompok anak yang diberikan permainan kooperatif tanpa kompetisi. Hal ini disebabkan bermain permainan kooperatif secara kompetisi memperlihatkan sikap fokus dan peran aktif anak dalam menyelesaikan permainan. Interaksi yang terjadi antar anak pun sangat intens terlihat seperti berdiskusi untuk memecahkan masalah yang dihadapi bersama.

Selanjutnya hasil penelitian juga menunjukkan bahwa terdapat interaksi yang signifikan antara kegiatan bermain permainan kooperatif secara kompetisi maupun bermain permainan kooperatif tanpa kompetisi terhadap regulasi emosi anak TK kelompok B. Untuk anak dengan kecerdasan interpersonal yang tinggi lebih tepat digunakan permainan kooperatif secara kompetisi, karena terlihat bahwa anak yang memiliki kecerdasan interpersonal yang tinggi tidak pernah ragu untuk menjalin hubungan dengan siapapun dan senang bermain kooperatif. Hal ini yang membantu anak untuk memahami lebih dalam emosi-emosi yang dirasakan diri sendiri maupun yang ditampilkan orang lain. Kecerdasan interpersonal yang tinggi juga baik dalam memimpin sebuah kelompok terlihat saat anak menyelesaikan masalah yang sedang dihadapi secara kelompok dimulai dari perencanaan sampai dengan proses penyelesaian masalah dapat diselesaikan secara bersama-sama. Sedangkan untuk anak dengan kecerdasan interpersonal rendah juga lebih baik menggunaka permainan kooperatif secara kompetisi, karena dengan adanya kompetisi memberikan motivasi lebih untuk anak bersama-sama menyelesaikan masalah yang dihadapi. Hal lainnya terlihat dengan bermain permainan kooperatif secara kompetisi dengan anak yang memiliki kecerdasan interpersonal tinggi memberikan dorong anak yang memiliki kecerdasan interpersonal rendah untuk ikut terlibat dan berinteraksi yang lebih intens. 


\section{REFERENSI}

Amstrong, T. (2014). Kecerdasan jamak. Jakarta: Indeks.

Davis, E. L., \& Levine, L. J. (2013). Emotion Regulation Strategies That Promote Learning: Reappraisal Enhances Children's Memory for Educational Information. Child Development, 84(1), 361-374. https://doi.org/10.1111/j.1467-8624.2012.01836.x

Dewi, N., Asri, I. G. A. A. S., \& Putra, M. (2016). Penerapan Metode Permainan Berbantuan Media Puzzle Untuk Meningkatkan Kemampuan Sosial Pada Anak. E-Journal Pendidikan Anak Usia Dini Universitas Pendidikan Ganesha, 4(1), 1-10.

Eisenberg, N. (2010). Children's emotion-related regulation. San Diego: Academic Press.

Gardner, H. (2013). Multiple intelligence (1st ed.; Pray, ed.). Jakarta: Daras Buku.

Gross, J. J., \& Thompson, R. A. (2014). Emotion Regulation: Conceptual Foundations. In J. J. Gross (Ed.), Handbook of emotion regulation (p. 3-24). New York: The Guilford Press.

Kurniati. (2016). Permainan tradisional dan peranannya dalam mengembangkan keterampilan sosial anak. Jakarta: Kencana Prenada Media Group.

Lwin, May, \& Khoo, A. (2008). Cara mengembangkan berbagai komponen kecerdasan. Jogyakarta: Grasindo.

Morris, A., Silk, S., Steinberg, L., Myers, S., \& Robinson, R. (2007). The role of the family context in the development of emotion regulation. Journal of Social Development, 16, 361-388.

Papalia, D., \& Old, S. (2010). Human Development (Psikologi Perkembangan) (Kesembilan). Jakarta: Kencana Prenada Media Group.

Röll, J., Koglin, U., \& Petermann, F. (2012). Emotion regulation and childhood aggression: Longitudinal associations. Child Psychiatry \& Human Development, 43(6), 909-923.

Rusman. (2017). Belajar dan pembelajaran berorientasi standart proses pendidikan (1st ed.). Jakarta: Kharisma Putra Utama.

Santrock. J. (2010). Life-span development (13th ed.; M. Ryan, ed.). New York: Mc-Graw-Hill.

Santrock, J. (2014). Child development (14th ed.). New York: Mc-Graw-Hill.

Slavin, E. (2010). Cooperative learning: Riset dan Praktik. Bandung: Nusa Media. 
INDONESIAN JOURNAL OF EDUCATIONAL COUNSELING 2020, 4(1), 31-40

Syamsidah. (2015). Permainan kooperatif untuk PAUD dan TK. Yogyakarta: Penerbit Gava Media. 